\title{
Spherical crystals of celecoxib to improve solubility, dissolution rate and micromeritic properties
}

\author{
VENKADARI RAMMOHAN GUPTA ${ }^{1 *}$ \\ SRINIVAS MUTALIK ${ }^{2}$ \\ MADHOBHAI M. PATEL ${ }^{3}$ \\ GIRISH K. JANI ${ }^{4}$ \\ ${ }^{1}$ Department of Pharmaceutics \\ N. E. T. Pharmacy College Navodaya \\ Nagar, Mantralayam Road \\ Raichur-584103, India \\ 2 Department of Pharmaceutics \\ Manipal College of Pharmaceutical Sciences \\ Manipal-576104, India \\ ${ }^{3}$ Vice Chancellor \\ Hemachandracharya North Gujarat \\ University Patan, India \\ 4 Department of Pharmaceutics \\ L. M. College of Pharmacy Navrangpura \\ Ahmedabad, India
}

Accepted January 31, 2007

\begin{abstract}
Celecoxib spherical agglomerates were prepared with polyvinylpyrrolidone (PVP) using acetone, water and chloroform as solvent, non-solvent and bridging liquid, respectively. The agglomerates were characterized by differential scanning calorimetry (DSC), X-ray diffraction (XRD), IR spectroscopic studies and scanning electron microscopy (SEM). The IR spectroscopy and DSC results indicated the absence of any interactions between drug and additives. XRD studies showed a decrease in crystallinity in agglomerates. The crystals exhibited significantly improved micromeritic properties compared to pure drug. The loading efficiency (\% or mg drug per $100 \mathrm{mg}$ crystals) was in the range of $93.9 \pm 2.3$ and $97.3 \pm 1.3 \%(n=3)$ with all formulations. The aqueous solubility and dissolution rate of the drug from crystals was significantly $(p<0.05)$ increased (nearly two times). The solubility and in vitro drug release rates increased with an increase in PVP concentration (from 2.5 to $10 \%$ ). The SEM studies showed that the crystal posseses a good spherical shape with smooth and regular surface.
\end{abstract}

Keywords: celecoxib, spherical crystallization, solubility, dissolution rate, micromeritic properties

Direct tabletting of pharmaceutical materials is desirable to reduce the cost of production (1). However, compressing a high-dosed drug directly requires good micromeritic properties, such as flowability, and good and reproducible compression behavior. Spherical crystallization technique transforms directly the fine particles produced in crystallization or in the reaction process into a spherical shape. Agglomerates exhibit improved secondary characteristics, like flowability and compressibility, so that direct tabletting or coating is possible without further processing (mixing, agglomeration, sieving, etc.) $(2,3)$. Celecoxib, a non-steroidal anti-inflammatory drug (NSAID), is the first selective cyclooxygenase- 2 inhibitor used in the treatment of osteoarthritis and rheumatoid arthritis in adult patients (4). Celecoxib exhibits poor flow and compression charac-

\footnotetext{
*Correspondence, e-mail: vrmgupta_05@yahoo.co.in
} 
teristics and is hence a suitable candidate for spherical crystallization process to improve the flow properties and compressibility. Also, celecoxib shows incomplete and poor oral bioavailability due to low aqueous solubility (5). Hence, the improvement of aqueous solubility in such a case is a valuable goal to improve therapeutic efficacy (6). Apart from particle enlargement, this technique has also been applied for various purposes such as taste masking and particle size enlargement (7-10). Spherical crystallization of celecoxib with hydroxypropyl methyl cellulose has been investigated to improve the micromeritic properties of celecoxib but the aqueous solubility of spherical crystallized drug was not satisfactorily improved (11). There are no reports available on the spherical crystallization of celecoxib by using a more hydrophilic polymer, polyvinylpyrrolidone K-30 (PVP), to improve aqueous solubility and dissolution rates in addition to improving its micrometric properties, and hence the present work has been undertaken with this objective.

\section{EXPERIMENTAL}

\section{Materials}

Celecoxib was a gift sample from Aurobindo Pharma, India. PVP was purchased from s.d. Fine Chemicals, India. All other chemicals used were of analytical reagent grade.

\section{Spherical crystallization}

A solution of celecoxib $(2 \mathrm{~g})$ in acetone $(3 \mathrm{~mL})$ was added to a solution of hydrophilic polymer (PVP, 2.5-10\%, $\mathrm{m} / \mathrm{V}$ ) in $100 \mathrm{~mL}$ distilled water. The mixture was stirred continuously using a mechanical stirrer (Remi Motors, India) at $500 \mathrm{rpm}$ to obtain spherical agglomerates. The bridging liquid (chloroform, $0.5 \mathrm{~mL}$ ) was added dropwise. The agglomerates were separated by filtration using Whatman filter paper (No. 1) and dried for $24 \mathrm{~h}$ at room temperature. The physical mixture of drug and polymer (celecoxib+ PVP) was prepared by triturating 1:1 ratio of celecoxib and PVP using mortar and pestle.

\section{Infrared spectroscopy, differential scanning calorimetry (DSC) and X-ray diffraction studies}

The infrared (IR) spectra of powder celecoxib, physical mixture and the agglomerates were recorded on an IR-spectrophotometer (FTIR 8300, Shimadzu, Japan) by the $\mathrm{KBr}$ pellet technique. Differential scanning calorimetry (DSC) analysis was performed using a DSC-60 calorimeter (Shimadzu). The instrument was equipped with a TA-60WS thermal analyzer, FC-60A flow controller and TA-60 software. Samples of celecoxib, physical mixture and agglomerates were hermetically sealed in an aluminum crucible and heated at a rate of $5^{\circ} \mathrm{C} \mathrm{min}-1$ up to $200{ }^{\circ} \mathrm{C}$ under a nitrogen atmosphere $\left(30 \mathrm{~mL} \mathrm{~min}^{-1}\right)$. A similar empty pan was used as the reference. Powder X-ray diffraction patterns (XRD) of the pure drug and spherical agglomerates were obtained using an X-ray diffractometer (Seifert 3003 TT, Germany). 
V. R. M. Gupta et al:: Spherical crystals of celecoxib to improve solubility, dissolution rate and micromeritic properties, Acta Pharm. $\mathbf{5 7}$ (2007) 173-184.

\section{Micromeritic properties}

The particle size distribution was studied by the sieve analysis method (12). The shape of the crystals was observed under an optical microscope (10x magnification) attached to a computer. The loose bulk density (LBD) and tapped bulk density (TBD) of plain celecoxib and its spherical crystals were determined using a bulk density test apparatus (Kumar Industries, India). Carr's index and Hausner's ratio were calculated using LBD and TBD values (13).

The angle of repose was assessed by the fixed funnel method (12). A known amount of agglomerates was allowed to flow through a funnel fixed at a constant height $(h)$ and the height and diameter $(2 r)$ of the pile of powder were measured to calculate the angle of repose as $\operatorname{tg} \alpha=h / r$.

\section{Scanning electron microscopy}

The surface morphology of the agglomerates was assessed by scanning electron microscopy (SEM) (Leica StereoScan 430, LEO, UK). The crystals were splutter coated with gold before scanning.

\section{Drug loading}

The drug loading efficiency of crystals was determined by dissolving $100 \mathrm{mg}$ of crystals in $100 \mathrm{~mL}$ of methanol, followed by measuring the absorbance of appropriately diluted solution spectrophotometrically (PharmaSpec UV-1700, UV-Vis spectrophotometer, Shimadzu) at $253.5 \mathrm{~nm}$.

\section{Solubility studies}

A quantity of crystals (about $100 \mathrm{mg}$ ) was shaken with $10 \mathrm{~mL}$ of distilled water or a solution of sodium lauryl sulphate (SLS) $(2 \%, m / V)$ in a shaking water bath (100 agitations per $\mathrm{min}$ ) for $24 \mathrm{~h}$ at room temperature. The solution was then passed through a $0.45 \mu \mathrm{m}$ membrane filter and the amount of the drug dissolved was analyzed spectrophotometrically.

\section{In vitro dissolution studies}

The in vitro dissolution studies were carried out using an 8 station USP 23 dissolution testing apparatus (Electrolab, India) (5). The dissolution medium used was $900 \mathrm{~mL}$ of distilled water or $2 \%, \mathrm{~m} / \mathrm{V}$ SLS. The agglomerates containing $100 \mathrm{mg}$ of celecoxib were weighed and filled into a hard gelatin capsule. In the case of pure drug, $100 \mathrm{mg}$ of pure celecoxib was weighed and filled into a capsule. The capsule was then introduced into the dissolution medium. The medium was stirred at $75 \mathrm{rpm}$ using a paddle at $37 \pm$ $0.5^{\circ} \mathrm{C}$. The samples were collected and analyzed spectrophotometrically.

\section{Statistical analysis}

The results were analyzed by two tailed Student's $t$-test using the Graph Pad Instat Software (GPIS; Version: 1.13) (20). The mean dissolution time (MDT) was calculated using the Origin software. 
V. R. M. Gupta et al:: Spherical crystals of celecoxib to improve solubility, dissolution rate and micromeritic properties, Acta Pharm. $\mathbf{5 7}$ (2007) 173-184.

\section{RESULTS AND DISCUSSION}

\section{Formulation development}

Spherical agglomerates of celecoxib were prepared by the simple agglomeration technique using a three solvent system. It involves a good solvent, a poor solvent and a bridging liquid. The selection of these solvents depends on the miscibility of the solvents and the solubility of drug in individual solvents. Accordingly, acetone, chloroform and water were selected as a good solvent, bridging liquid and poor solvent, respectively. These solvents have been used successfully in previous studies. Chloroform, although currently not widely used, has shown high application in the formation of spherical crystals $(11,14)$. Hence, this solvent system was used in the present study. Agglomerates were formed by agitating the crystals in a liquid suspension and adding a bridging liquid, which preferentially wets the crystal surface to cause binding. The addition of bridging liquid (chloroform) promotes the formation of liquid bridges between the drug crystals to form spherical agglomerates. The spherically agglomerated crystals are formed by coalescence of these dispersed crystals (15). Generally hydrophilic materials, like hydroxypropyl methylcellulose, hydroxypropyl cellulose, etc., are used to impart strength and sphericity to the agglomerates $(11,14)$. However, the aqueous solubility of celecoxib in spherical crystals was not satisfactorily improved by using hydroxypropyl methylcellulose (11). In this study, PVP, which is comparatively more hydrophilic, was used to increase aqueous solubility of the drug along with improving the micromeritic properties.

\section{IR, DSC and XRD studies}

The possible interaction between the drug and the carrier was studied by IR spectroscopy and DSC. The principal IR peaks of pure celecoxib, physical mixture and spherical crystals are shown in Table I. IR spectra of celecoxib showed characteristic peaks at 3341.51 (-NH str., primary amine), 1164.58 and $1347.75 \mathrm{~cm}^{-1}(\mathrm{~S}=\mathrm{O}$ asymmetric and symmetric str., respectively) and, 1274.96 and $1229.99 \mathrm{~cm}^{-1}\left(-\mathrm{CF}_{3}\right)(11)$. There were no considerable changes in the IR peaks of the physical mixture and spherical crystals when compared to pure celecoxib. If there is any strong interaction between drug and carrier, it often leads to identifiable changes in the IR profile and melting point of the drug. The results of IR spectra indicated the absence of any well-defined interaction between celecoxib and PVP in the presence of acetone, chloroform and water. This was further supported by DSC results.

The DSC patterns of pure celecoxib and its crystal forms are shown in Fig. 1. Pure celecoxib showed a sharp endotherm at $163.08{ }^{\circ} \mathrm{C}$ corresponding to its melting point. There was a negligible change in the melting endotherms of the physical mixture and prepared spherical crystals compared to pure drug (162.3 and $161.70{ }^{\circ} \mathrm{C}$, respectively). PVP alone did not show any endothermic peak in DSC studies. This observation further supports the IR spectroscopy results, which indicated the absence of any interactions between the drug, PVP and additives used in the preparation. However, there was a decrease, although very small, in the melting point of the drug in the physical mixture and final spherical crystals compared to that of pure celecoxib. Similar results were observed in an earlier study, where the melting endotherm of nimesulide decreased as the solubility of the drug from the prepared crystals was increased $(18,19)$. 
V. R. M. Gupta et al:: Spherical crystals of celecoxib to improve solubility, dissolution rate and micromeritic properties, Acta Pharm. $\mathbf{5 7}$ (2007) 173-184.

Table I. Major IR peaks of pure celecoxib, physical mixture and spherical crystals

\begin{tabular}{lcl}
\hline Sample & Major peaks (wave numbers, $\mathrm{cm}^{-1}$ ) & Chemical moiety \\
\hline & 3341.51 & $-\mathrm{NH}$ str., primary amine \\
Pure celecoxib & 1164.58 & $\mathrm{~S}=\mathrm{O}$ asymmetric str. \\
& 1347.75 & $\mathrm{~S}=\mathrm{O}$ symmetric str. \\
& $1274.96,1229.99$ & $-\mathrm{CF}_{3}$ \\
Physical mixture & 3341.15 & $-\mathrm{NH}$ str., primary amine \\
& 1164.66 & $\mathrm{~S}=\mathrm{O}$ asymmetric str. \\
& 1347.68 & $\mathrm{~S}=\mathrm{O}$ symmetric str. \\
Crystals $(10 \% m / V$ PVP) & $1274.84,1229.95$ & $-\mathrm{CF}_{3}$ \\
& 3341.15 & $-\mathrm{NH}$ str., primary amine \\
& 1164.58 & $\mathrm{~S}=\mathrm{O}$ asymmetric str. \\
& 1347.68 & $\mathrm{~S}=\mathrm{O}$ symmetric str. \\
\hline
\end{tabular}

a)

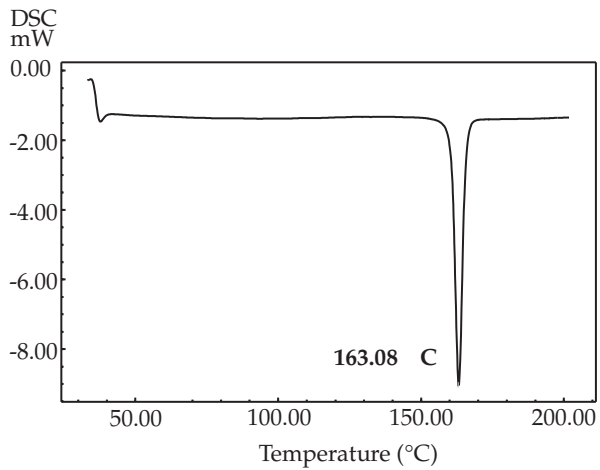

c)

DSC
mW

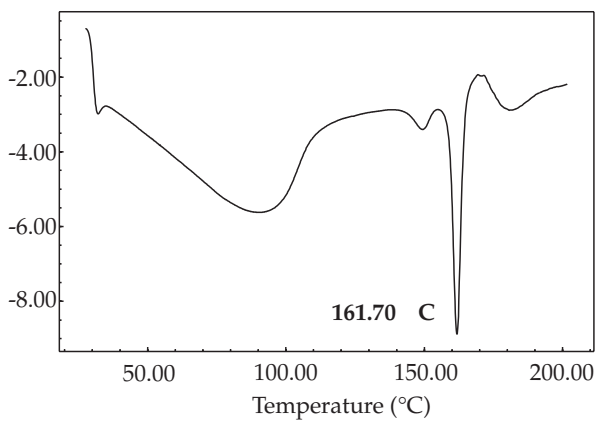

b)

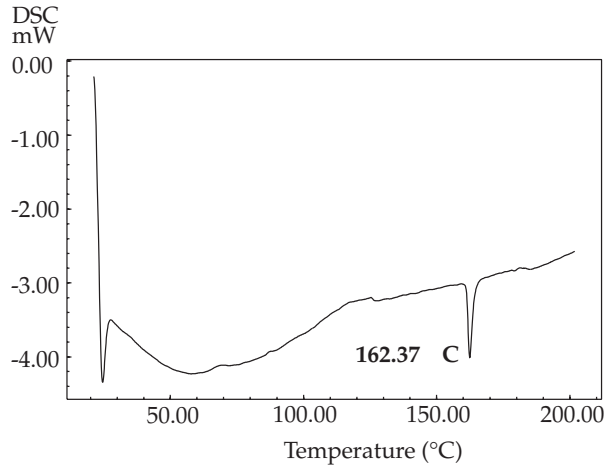

d)

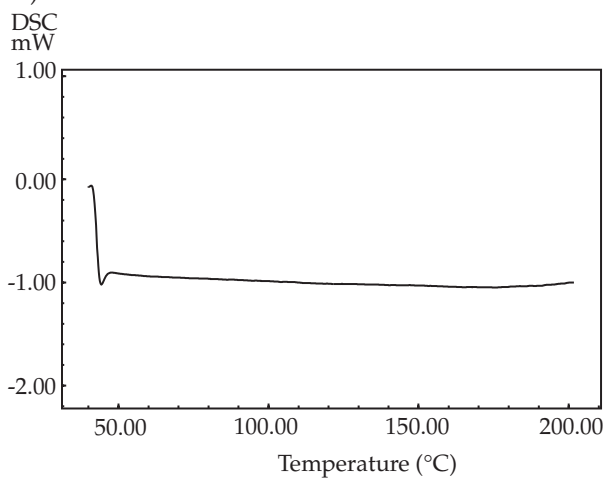

Fig. 1. DSC patterns of celecoxib, physical mixture, PVP and spherical crystals: a) pure celecoxib, b) physical mixture, c) spherical crystals (10\% PVP), d) PVP. 
V. R. M. Gupta et al.: Spherical crystals of celecoxib to improve solubility, dissolution rate and micromeritic properties, Acta Pharm. $\mathbf{5 7}$ (2007) 173-184.

a)

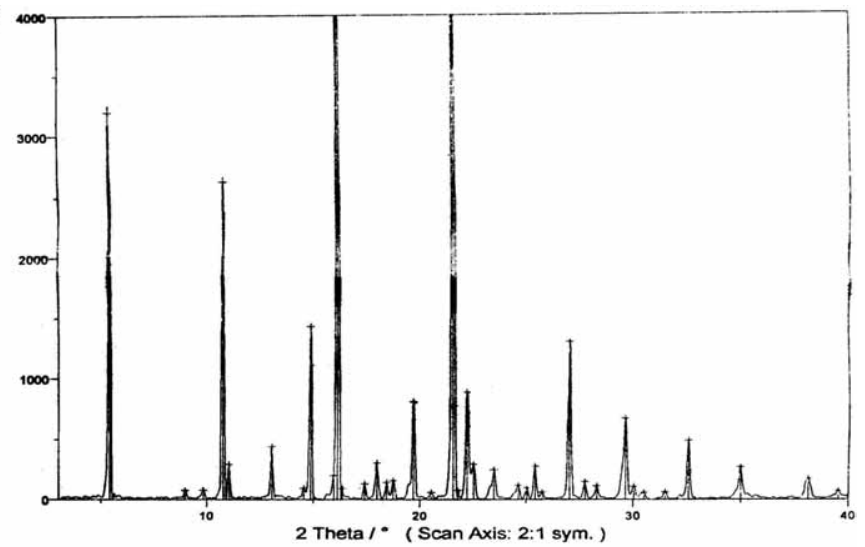

b)

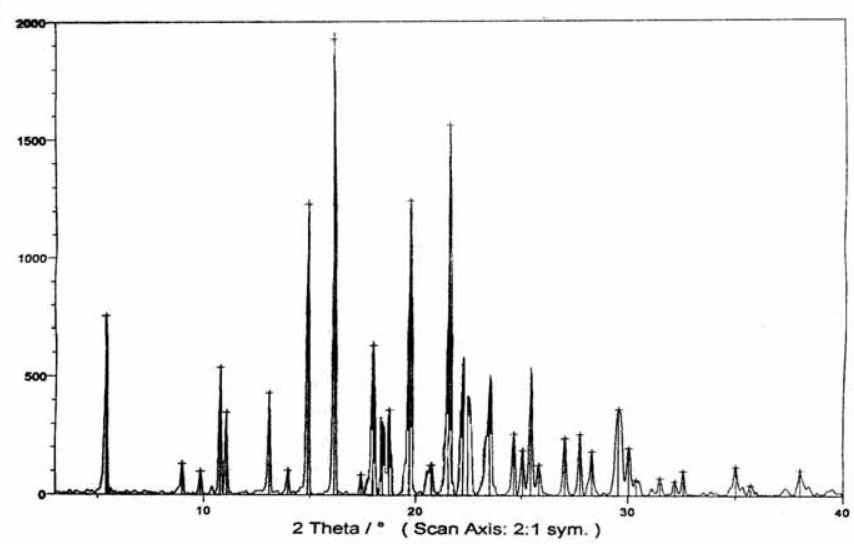

Fig. 2. X-ray diffraction spectra: a) pure drug, b) spherical crystals (10\% PVP).

The results of the powder X-ray diffraction pattern of celecoxib and spherical agglomerates are shown in Fig. 2. Pure drug exhibited intense and long peaks (Fig. 2a) whereas spherical agglomerates showed a halo pattern with less intense peaks, which indicate a considerable decrease in crystallinity of the drug in the form of spherical agglomerates (Fig. 2b). The results also indicated that polymorphic changes had not been detected after recrystallization, since all XRD peaks of the spherical agglomerates were consistent with the pattern of original drug crystals. These results are in accord with earlier reports $(11,16)$.

\section{Micromeritic properties}

The mean particle diameter of agglomerates is shown in Table II. The pure drug exhibited a very small particle size $(85.55 \pm 10.25 \mu \mathrm{m}, n=3)$ whereas the size of prepared 
V. R. M. Gupta et al:: Spherical crystals of celecoxib to improve solubility, dissolution rate and micromeritic properties, Acta Pharm. $\mathbf{5 7}$ (2007) 173-184.

agglomerates was found between $201.12 \pm 10.18$ and $235.11 \pm 12.23 \mu \mathrm{m}, n=3$, which is significantly different from that of pure drug $(p<0.05)$. There was uniformity in batch-to-batch with respect to the size range of crystals. The size of the crystals increased with an increase in the PVP concentration. The shape of the crystals, when observed using an optical microscope (figures not shown), was spherical in all the prepared crystal formulations.

Table II. Micromeritic properties of agglomerates and pure druga

\begin{tabular}{lcccccc}
\hline $\begin{array}{l}\text { Spherical } \\
\text { crystals }\end{array}$ & $\begin{array}{c}\text { LBD } \\
\left(\mathrm{g} \mathrm{mL}^{-1}\right)\end{array}$ & $\begin{array}{c}\text { TBD } \\
\left(\mathrm{g} \mathrm{mL}^{-1}\right)\end{array}$ & $\begin{array}{c}\text { Carr's index } \\
(\%)\end{array}$ & $\begin{array}{c}\text { Hausner's } \\
\text { ratio }\end{array}$ & $\begin{array}{c}\text { Angle of } \\
\text { repose }\left({ }^{\circ}\right)\end{array}$ & $\begin{array}{c}\text { Particle size } \\
(\mu \mathrm{m})\end{array}$ \\
\hline PVP $(2.5 \%)$ & $0.42 \pm 0.01^{\mathrm{b}}$ & $0.45 \pm 0.01^{\mathrm{b}}$ & $10.20 \pm 1.51^{\mathrm{b}}$ & $1.18 \pm 0.01^{\mathrm{b}}$ & $29.31 \pm 1.23$ & $201.12 \pm 10.18^{\mathrm{b}}$ \\
PVP $(5.0 \%)$ & $0.40 \pm 0.02^{\mathrm{b}}$ & $0.45 \pm 0.01^{\mathrm{b}}$ & $10.10 \pm 2.36^{\mathrm{b}}$ & $1.10 \pm 0.02^{\mathrm{b}}$ & $26.47 \pm 2.31$ & $218.13 \pm 12.10^{\mathrm{b}}$ \\
PVP (7.5\%) & $0.37 \pm 0.01^{\mathrm{b}}$ & $0.41 \pm 0.01^{\mathrm{b}}$ & $10.00 \pm 2.12^{\mathrm{b}}$ & $1.10 \pm 0.01^{\mathrm{b}}$ & $25.61 \pm 1.89$ & $230.25 \pm 11.77^{\mathrm{b}}$ \\
PVP (10.0\%) & $0.39 \pm 0.01^{\mathrm{b}}$ & $0.44 \pm 0.01^{\mathrm{b}}$ & $10.10 \pm 2.69^{\mathrm{b}}$ & $1.10 \pm 0.01^{\mathrm{b}}$ & $22.88 \pm 1.65$ & $235.11 \pm 12.23^{\mathrm{b}}$ \\
Pure celecoxib & $0.30 \pm 0.01$ & $0.52 \pm 0.02$ & $42.00 \pm 2.36$ & $1.69 \pm 0.03$ & - & $85.55 \pm 10.25$ \\
\hline
\end{tabular}

LBD - loose bulk density, TBD - tapped bulk density.

a Mean \pm SEM, $n=3$.

b Significantly different compared to pure celecoxib $(p<0.05)$.

The results of loose bulk density (LBD) and tapped bulk density (TBD) are presented in Table II. These parameters were used to assess the packability of the crystals. The pure drug powder was more bulky and fluffy, which was indicated by the lowest LBD value $\left(0.30 \pm 0.01 \mathrm{~g} \mathrm{~mL}^{-1}, n=3\right)$. The highest TBD value $\left(0.52 \pm 0.02 \mathrm{~g} \mathrm{~mL}^{-1}, n=3\right)$ of pure drug indicates a high intergranular space between particles. In contrast, the spherical agglomerates exhibited higher LBD $\left(0.37 \pm 0.01\right.$ to $\left.0.42 \pm 0.01 \mathrm{~g} \mathrm{~mL}^{-1}, n=3\right)$ and TBD $\left(0.41 \pm 0.01\right.$ to $\left.0.45 \pm 0.01 \mathrm{~g} \mathrm{~mL}^{-1}, n=3\right)$ values (12). These results indicate good packability of the prepared spherical crystals when compared with pure celecoxib.

The results of Carr's index, Hausner's ratio and angle of repose of spherical crystals in comparison with pure drug are presented in Table II. These parameters were used to assess the flow and compressibility properties of the agglomerates. Carr's index and Hausner's ratio of pure drug were $42.00 \pm 2.36 \%$ and $1.69 \pm 0.03(n=3)$, respectively, indicating extremely poor flow properties. The powder could not pass through the funnel during the angle of repose experiment. The poor flow of celecoxib could be due to the irregular shape and high fineness of the powder, which posed hurdles in the uniform flow from the funnel. On the other hand, all the prepared crystals exhibited low Carr's index, Hausner's ratio and angle of repose values, indicating excellent flow properties and compressibility (Carr's index: $10.00 \pm 2.12$ to $10.20 \pm 1.51 \%, n=3$; Hausner's ratio: $1.10 \pm$ 0.01 to $1.18 \pm 0.01, n=3$; angle of repose: $22.88 \pm 1.65$ to $29.31 \pm 1.23^{\circ}, n=3$ ). The improved flowability and compressibility of spherical agglomerates may be due to the sphericity, regular and larger size of crystals $(11,13,15)$. Among all the prepared spherical crystals, the agglomerates prepared with $10 \%, m / V$, PVP exhibited good micromeritic properties. 
V. R. M. Gupta et al:: Spherical crystals of celecoxib to improve solubility, dissolution rate and micromeritic properties, Acta Pharm. $\mathbf{5 7}$ (2007) 173-184.

\section{Scanning electron microscopy}

The results of surface morphology studies are shown in Fig. 3. The pure celecoxib powder was in the form of fine needles, which is in agreement with the earlier report (Fig. 3a) (11). This long-needle form of celecoxib leads to very poor flow and compressional difficulties. The surface morphology of prepared agglomerates is shown in Fig. 3b (200x) and Fig. 3c (50x). These photo-micrographs show that the prepared agglomerates were spherical in shape with a smooth and regular surface, which enabled them to flow very easily.

\section{Drug loading and solubility studies}

The results of drug loading efficiency and aqueous solubility are shown in Table III. The drug loading of the crystals was uniform among the different spherical crystals prepared and ranged from $93.9 \pm 2.3$ to $97.3 \pm 1.3(n=3)$, indicating negligible loss of drug during the crystallization process. The results of solubility studies indicate that pure celecoxib possesses a very low solubility in water $(2.55 \pm 0.12 \mu \mathrm{g} \mathrm{mL}-1, n=3)$; the drug solubility from the crystals increased significantly $(p<0.05)$, demonstrating that the incorporation of PVP enhances the drug solubility by improving wettability. As the concentration of PVP increased, the drug solubility also increased. Maximum solubility was observed at $10 \%(m / V)$ PVP $(5.96 \pm 0.69 \mu \mathrm{g} \mathrm{mL}-1, n=3)$. Similar results were observed with $2 \%(m / V)$ SLS (Table III).

a)

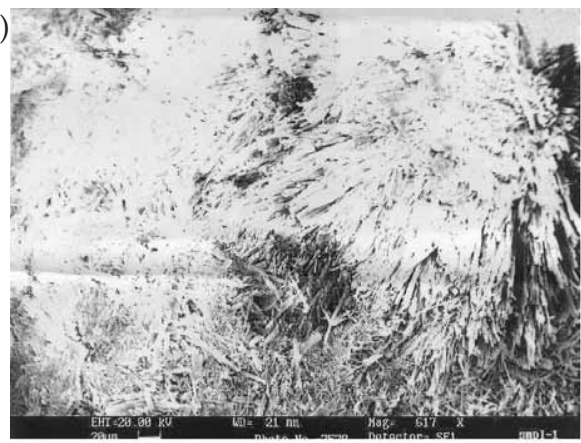

C)

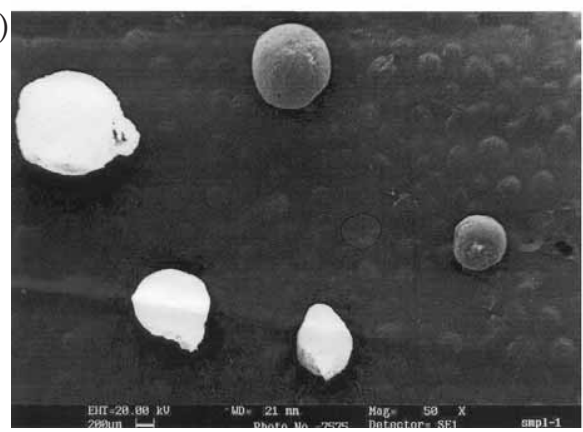

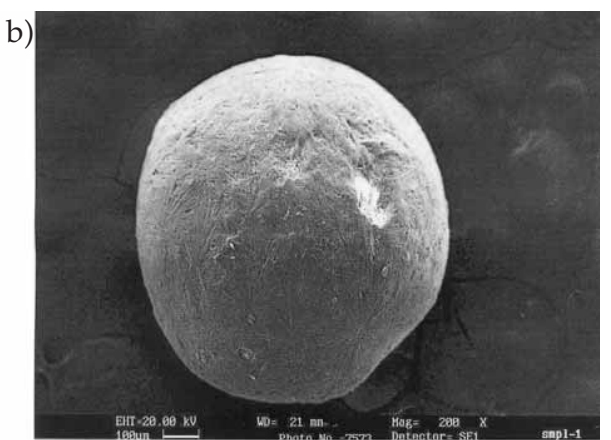

Fig. 3. Scanning electron micrographs of: a) pure celecoxib, b) spherical crystals (200x), c) spherical crystals (50x). 
V. R. M. Gupta et al.: Spherical crystals of celecoxib to improve solubility, dissolution rate and micromeritic properties, Acta Pharm. 57 (2007) 173-184.

Table III. Drug loading efficiency and solubility data for the agglomerates and pure druga

\begin{tabular}{lccc}
\hline \multirow{2}{*}{ Spherical crystals } & Drug loading $(\%)^{\mathrm{b}}$ & \multicolumn{2}{c}{ Solubility $\left.(\mu \mathrm{g} \mathrm{mL})^{-1}\right)$} \\
\cline { 3 - 4 } & & Water & SLS $(2 \%, m / V)$ \\
\hline PVP $(2.5 \%)$ & $97.3 \pm 1.3$ & $4.02 \pm 0.25^{\mathrm{c}}$ & $468.1 \pm 10.1^{\mathrm{c}}$ \\
PVP $(5.0 \%)$ & $95.8 \pm 1.3$ & $4.54 \pm 0.69^{\mathrm{c}}$ & $496.5 \pm 12.3^{\mathrm{c}}$ \\
PVP $(7.5 \%)$ & $94.6 \pm 2.1$ & $5.28 \pm 0.95^{\mathrm{c}}$ & $542.2 \pm 13.3^{\mathrm{c}}$ \\
PVP $(10.0 \%)$ & $93.9 \pm 2.3$ & $5.96 \pm 0.69^{\mathrm{c}}$ & $563.5 \pm 19.3^{\mathrm{c}}$ \\
Pure celecoxib & $100.0 \pm 0.0$ & $2.55 \pm 0.12$ & $345.5 \pm 18.6$ \\
\hline
\end{tabular}

a Mean \pm SEM, $n=3$.

b Drug loading is expressed as \% or mg of drug per $100 \mathrm{mg}$ of crystals.

c Significantly different compared to pure celecoxib $(p<0.05)$.

\section{In vitro dissolution studies}

The results of in vitro dissolution studies are shown in Fig. 4 and Table IV. Pure celecoxib exhibited less release at the end of $180 \mathrm{~min}$ in water $(1.8 \pm 0.2 \%, n=3)$; spherical crystals improved the dissolution rate of celecoxib in water as dissolution medium (increase from 26.7 to $63.9 \%$ compared to that of pure drug). The dissolution rate was increased with an increase in PVP concentration. The mean dissolution time (MDT) for pure celecoxib was $49.25 \pm 3.01 \mathrm{~min}, n=3$; but in crystals containing 2.5, 5.0, 7.5 and $10.0 \%$ PVP were low when compared to that of pure drug in water $(21.9 \pm 3.2,20.2 \pm 4.6$, $20.1 \pm 5.7$ and $18.5 \pm 4.0 \mathrm{~min}, n=3$, respectively). This could be due to increased wettability of the drug by the presence of PVP, which might have increased the drug release from crystals in the initial time period. The MDT was reduced significantly $(p<0.05)$ with an increase in PVP concentration. The crystals prepared with $10 \%(\mathrm{~m} / \mathrm{V})$ PVP exhibited maximum dissolution $(3.0 \pm 0.2 \%$ in $180 \mathrm{~min}, n=3)$ and very low MDT values
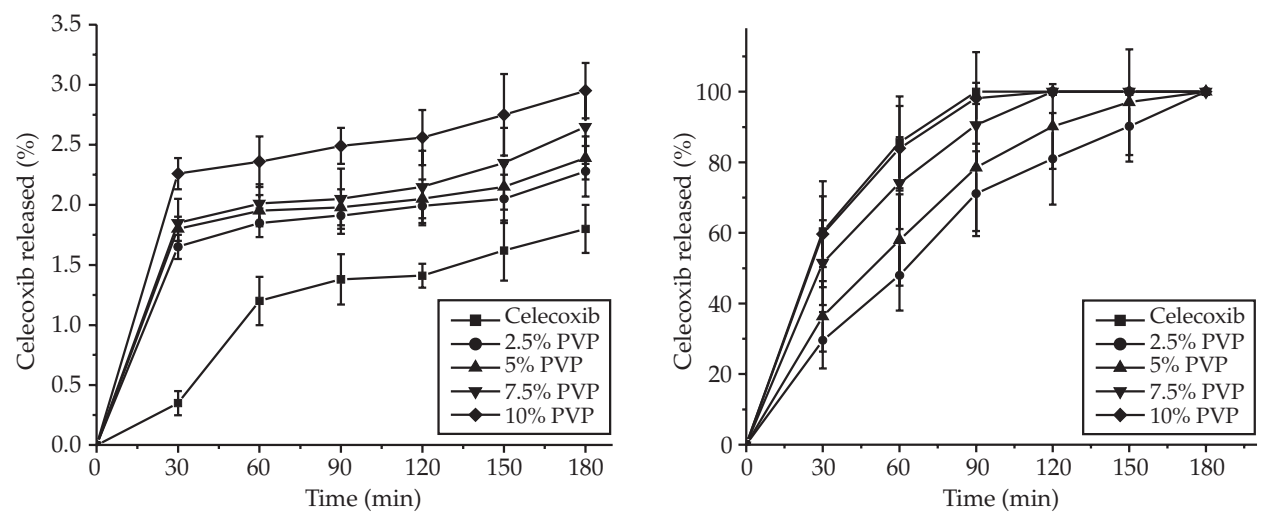

Fig. 4. Dissolution profile of pure drug and agglomerates: a) water, b) SLS $(2 \%, m / V)$. Mean \pm SEM, $n=3$. 
V. R. M. Gupta et al:: Spherical crystals of celecoxib to improve solubility, dissolution rate and micromeritic properties, Acta Pharm. $\mathbf{5 7}$ (2007) 173-184.

Table IV. Drug release and $M D T^{a}$

\begin{tabular}{|c|c|c|c|c|}
\hline \multirow[b]{2}{*}{$\begin{array}{l}\text { Spherical } \\
\text { crystals }\end{array}$} & \multicolumn{2}{|c|}{ Water } & \multicolumn{2}{|c|}{$\operatorname{SLS}(2 \%, m / V)$} \\
\hline & $\begin{array}{l}\text { Celecoxib } \\
\text { released }(\%) \\
\text { after } 3 \mathrm{~h}\end{array}$ & MDT (min) & $\begin{array}{l}\text { Celecoxib } \\
\text { released (\%) }\end{array}$ & MDT (min) \\
\hline PVP (2.5\%) & $2.3 \pm 0.4$ & $21.89 \pm 3.23^{b}$ & $\begin{array}{c}100.0 \pm 0.0 \\
\text { (after 3h) }\end{array}$ & $63.67 \pm 5.36^{\mathrm{b}}$ \\
\hline PVP (5.0\%) & $2.4 \pm 0.6$ & $20.19 \pm 4.56^{\mathrm{b}}$ & $\begin{array}{c}100.0 \pm 0.0 \\
\text { (after } 3 \mathrm{~h})\end{array}$ & $49.97 \pm 4.59^{\mathrm{b}}$ \\
\hline PVP (7.5\%) & $2.7 \pm 0.5$ & $20.08 \pm 5.66^{\mathrm{b}}$ & $\begin{array}{c}100.0 \pm 0.0 \\
\text { (after } 2 \mathrm{~h} \text { ) }\end{array}$ & $30.23 \pm 2.98^{b}$ \\
\hline PVP (10.0\%) & $3.0 \pm 0.2^{b}$ & $18.50 \pm 4.01^{b}$ & $\begin{array}{l}100.0 \pm 0.0 \\
\text { (after } 1.5 \mathrm{~h} \text { ) }\end{array}$ & $24.85 \pm 2.69^{b}$ \\
\hline Pure celecoxib & $1.8 \pm 0.2$ & $49.25 \pm 3.01$ & $\begin{array}{l}100.0 \pm 0.0 \\
\text { (after } 1.5 \mathrm{~h})\end{array}$ & $24.89 \pm 3.66$ \\
\hline
\end{tabular}

MDT - mean dissolution time.

a Mean \pm SEM, $n=3$.

b Significantly different compared to pure celecoxib $(p<0.05)$.

$(18.50 \pm 4.01 \mathrm{~min}, n=3)$ in water. The crystals as well as pure drug exhibited high dissolution in $2 \%, m / V$, SLS solution due to the surfactant effect on the drug and complete dissolution of drug was observed within 90 to $180 \mathrm{~min}$. In $2 \%(\mathrm{~m} / V)$ SLS solution as dissolution medium, owing to availability of a very large surface area due to fine particles, dissolution of pure drug was high $(100.0 \pm 0.0 \%$ in $90 \mathrm{~min}, n=3)$ with a low MDT value $(24.89 \pm 3.66 \mathrm{~min}, n=3)$. The crystals prepared with $10 \%(m / V)$ PVP showed also very high dissolution $(100.0 \pm 0.0 \%$ in $90 \mathrm{~min}, n=3)$ and a very low MDT value $(24.85 \pm 2.69$ min, $n=3)$ in comparison with crystals prepared with $2.5,5.0$ and $7.5 \%(m / V)$ of PVP. This indicates that celecoxib crystals prepared with 10\% PVP exhibit an excellent dissolution rate and aqueous solubility enhancing ability. However, the dissolution rate and solubility enhancing effect of spherical crystals is not clearly distinguished from that of pure drug in $2 \%$ SLS solution as dissolution medium. The presence of SLS in the dissolution medium increases drug wettability, which results in a higher dissolution rate and lower MDT values. Hence, the study points to the need for optimization of SLS concentration in the medium. The mechanism behind the solubility and dissolution rate enhancing effect of celecoxib in crystal form may resemble the solid dispersion mechanism despite the large particle size of the crystals. This effect may be due to improved wettability of the surface of crystals by the adsorption of PVP onto the surfaces of crystals (17). These results clearly reveal that the dissolution rate of celecoxib was increased in the form of spherical agglomerates when compared to its pure form. They also demonstrate that PVP is a suitable polymer for the preparation of spherical agglomerates of celecoxib. 
V. R. M. Gupta et al:: Spherical crystals of celecoxib to improve solubility, dissolution rate and micromeritic properties, Acta Pharm. $\mathbf{5 7}$ (2007) 173-184.

\section{CONCLUSIONS}

The present study shows that spherical agglomerates of celecoxib prepared with PVP exhibited improved micromeritic properties in addition to improving the solubility and dissolution rate. This technique may be applicable for producing oral solid dosage forms of celecoxib with improved dissolution rate and oral bioavailability. However, in vivo studies are required to confirm these results.

\section{REFERENCES}

1. R. F. Shangraw, Compressed Tablets by Direct Compression, in Pharmaceutical Dosage Forms: Tablets (Eds. H. A. Lieberman, L. Lachman and J. B. Schwartz), Vol. 1, Marcel Dekker, New York 1989, pp. 195-246.

2. P. K. Kulkarni and B. G. Nagavi, Spherical crystallization, Indian J. Pharm. Ed. 36 (2002) 66-71.

3. A. R. Paradkar, A. P. Pawar, K. R. Mahadik and S. S. Kadam, Spherical crystallization: A novel particle design technique, Indian Drugs 31 (1998) 229-233.

4. Martindale The Extra Pharmacopoeia, 32nd ed., The Pharmaceutical Press, London 1999, pp. 2-12.

5. G. V. M. M. Babu, V. G. Shankar, K. H. Sankar, A. Seshasayana, N. K. Kumar and K. V. R. Murthy, Development of dissolution medium for a poorly water soluble drug, celecoxib, Indian J. Pharm. Sci. 6 (2002) 588-590.

6. M. S. Nagarsenker and M. S. Joshi, Celecoxib-cyclodextrin systems: Characterization and evaluation of in vitro and in vivo advantages, Drug Dev. Ind. Pharm. 31 (2005) 169-178.

7. P. H. Pawar, A. P. Pawar, K. R. Mahadik and A. R. Paradkar, Evalution of tableting properties of agglomerates obtained by spherical crystallisation of trimethoprim, Indian J. Pharm. Sci. 60 (1998) 24-28.

8. M. C. Deshpande, K. R. Mahadik, A. P. Pawar and A. R. Paradkar, Evaluation of spherical crystallization as a particle size enlargement technique for aspirin, Indian J. Pharm. Sci. 59 (1997) 32-34.

9. A. Sano and Y. Kawashima, Particle design of tolbutamide in the presence of soluble polymer or surfactant by the spherical crystallization technique: improvement of dissolution rate, J. Pharm. Sci. 76 (1987) 471-474.

10. A. Sano, T. Kuriki, Y. Kawashima, H. Takenchi, T. Hino and T. Niwa, Particle design of tolbutamide by the spherical crystallization technique. III. Micromeritic properties and dissolution rate of tolbutamide spherical agglomerates prepared by the quasi-emulsion solvent diffusion method and the solvent change method, Chem. Pharm. Bull. 38 (1990) 733-739.

11. A. R. Paradkar, A. P. Pawar, J. K. Chordiya, V. B. Patil and A. R. Ketkar, Spherical crystallization of celecoxib, Drug Dev. Ind. Pharm. 28 (2002) 1213-1220.

12. A. Martin, P. Bustamante and A. Chun, Micromeritics, in Physical Pharmacy - Physical Chemical Principles in the Pharmaceutical Sciences, $4^{\text {th }}$ ed., Lippincott Williams and Wilkins, Baltimore 2002, pp. 423-452.

13. J. Wells, Pharmaceutical preformulation, the physicochemical properties of drug substances, in Pharmaceutics - the Science of Dosage Form Design, $2^{\text {nd }}$ ed. (Ed. M. E. Aulton), Churchill Livingstone, London 2002, pp. 113-138.

14. Y. Kawashima, M. Okumura and H. Takenaka, Spherical crystallization. Direct spherical agglomeration of salicylic acid crystals during crystallization, Science 216 (1982) 1127-1128. 
V. R. M. Gupta et al:: Spherical crystals of celecoxib to improve solubility, dissolution rate and micromeritic properties, Acta Pharm. $\mathbf{5 7}$ (2007) 173-184.

15. M. K. Chourasia, N. K. Jain, S. Jasin, N. K. Jain and S. K. Jain, Preparation and characterization of agglomerates of flurbiprofen by spherical crystallization technique, Indian J. Pharm. Sci. 3 (2003) 287-290.

16. P. DiMartino, C. Barthelemy, F. Piva, E. Joiris, G. F. Palmieri and S. Martelli, Improved dissolution behavior of fenbufen by spherical crystallization, Drug Dev. Ind. Pharm. 25 (1999) 1073-1081.

17. S. Kawashima, T. Handa, H. Takenchi, M. Okumura, H. Katou and O. Nagai, Crystal modification of phenytoin with polyethylene glycol for improving mechanical strength, dissolution rate and bio-availability by a spherical crystallization technique, Chem. Pharm. Bull. 34 (1986) 33763383.

18. A. Kapoor, D. K. Mujumdar and M. R. Yadav, Crystal forms of nimesulide - a sulfonanilide (non-steroidal anti-inflammatory drug), Indian J. Chem. B. 37 (1998) 572-575.

19. S. Mutalik, M. Venkatesh and N. Udupa, Fast analgesic activity from recrystallized nimesulide and its solid dispersion, Indian J. Physiol. Pharmacol. 1 (2002) 115-118.

20. S. Mutalik and N. Udupa, Pharmacological evaluation of membrane moderated transdermal system of glipizide, Clin. Exp. Pharmacol. Physiol. 1-2 (2006) 17-26.

\section{$S A \check{Z} E T A K$}

\section{Sferični kristali celekoksiba za poboljšanje topljivosti, oslobađanja i mikromeričnih svojstava}

VENKADARI RAMMOHAN GUPTA, SRINIVAS MUTALIK, MADHOBHAI M. PATEL i GIRISH K. JANI

U radu je opisana priprava sferičnih aglomerata sa celekoksibom koristeći polivinilpirolidon (PVP), aceton, vodu i kloroform. Aglomerati su karakterizirani diferencijalnom pretražnom kalorimetrijom (DSC), rentgenskom difrakcijom (XRD), IR spektroskopijom i pretražnom elektronskom mikroskopijom (SEM). IR i DSC pokazale su odsutnost bilo kakvih interakcija između ljekovite tvari i aditiva. XRD je pokazala smanjenje kristaliničnosti u aglomeratima. Aglomerati su pokazali značajno poboljšana mikromerična svojstva u odnosu na čisti lijek. Udio lijeka u njima bio je između $93.89 \pm 2.26$ i $97.32 \pm 1.29 \%$. Topljivost $\mathrm{u}$ vodi i oslobađanje ljekovite tvari iz aglomerata povećalo se skoro dva puta. Topljivost i in vitro oslobađanje povećale su se s povećanjem koncentracije PVP (od 2,5 do $10 \%$ ). SEM studije su pokazale da kristali imaju pravilan sferični oblik te glatku i pravilnu površinu.

Ključne riječi: celekoksib, sferična kristalizacija, topljivost, oslobađanje, mikromerična svojstva

Department of Pharmaceutics, N.E.T. Pharmacy College, Navodaya Nagar, Mantralayam Road Raichur-584103, India

Department of Pharmaceutics, Manipal College of Pharmaceutical Sciences Manipal-576104, India

Vice Chancellor, Hemachandracharya North Gujarat University, Patan, India 